\title{
PROTOTYPE ROBOT PENUNJUK LOKASI BIDANG BUKU BERBASIS LINE FOLLOWER PERPUSTAKAAN TANGERANG
}

\author{
Nasril Sany ${ }^{1}$ \\ Dian Sugiarto ${ }^{2}$ \\ Nur Hikmah ${ }^{3}$

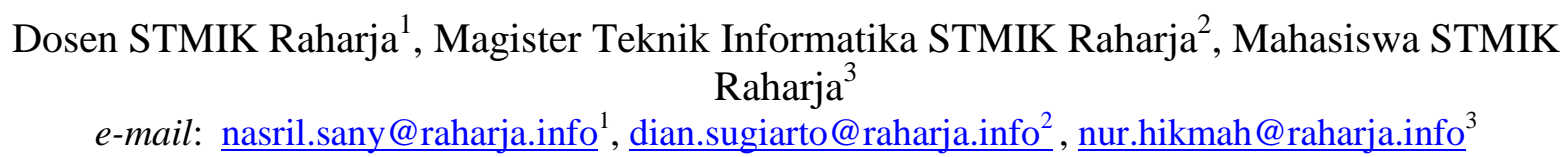

\begin{abstract}
ABSTRAKSI
Perpustakaan merupakan gudang ilmu pengetahuan sekaligus menjadi tempat rekreasi yang bermanfaat bagi semua kalangan. Di dalam perpustakaan terdapat banyak koleksi buku yang dapat digunakan untuk menambah wawasan dan ilmu pengetahuan. Seperti hal nya perpustakaan lain, perpustakaan Kota Tangerang memiliki koleksi buku yang cukup lengkap. Perkembangan sistem komputer secara signifikan telah menjadi kebutuhan dalam meningkatkan mutu pelayanan dan fasilitas yang diberikan kepada pengunjung. Penerapan dari perkembangan sistem komputer berupa robot yang akan mengantarkan pengunjung ke lokasi buku diharapkan akan meningkatkan mutu pelayanan pada Perpustakaan Kota Tangerang. Robot bekerja berdasarkan prinsip line follower yang menggunakan 4 buah sensor garis yang akan diproses oleh sebuah mikrokontroler arduino uno. Selain itu robot dilengkapi dengan sensor ultrasonik agar dalam proses berjalan robot tidak menabrak objek yang menghalanginya. Dengan adanya robot ini akan mempermudah pengunjung dalam mencari lokasi buku, serta membantu meningkatkan mutu pelayanan akan fasilitas yang diberikan pada pengunjung.
\end{abstract}

Kata Kunci: Perpustakaan, Mikrokontroler, Arduino Uno.

\section{ABSTRACT}

Library is a warehouse of science as well as a place of recreation that is beneficial to all circles. Inside the library there are many collections of books that can be used to add insight and knowledge. Like other libraries, the Tangerang City library has a fairly complete collection of books. The development of computer systems has significantly become a necessity in improving the quality of services and facilities provided to visitors. Implementation of the development of computer systems in the form of robots that will deliver visitors to the location of the book is expected to improve the quality of services at Tangerang City Library. The robot works based on the principle of line follower using 4 line sensors to be processed by an arduino uno microcontroller. In addition, the robot is equipped with ultrasonic sensors so that in the process of walking the robot does not hit an object that prevents it. With this robot will facilitate visitors in finding the location of the book, and help improve the quality of service will be provided to the visitors.

Keywords: Library, Microcontroller, Arduino Uno, Line Sensor, Ultrasonic Sensor.

\section{PENDAHULUAN}

Perpustakaan merupakan suatu tempat penyedia informasi, ilmu pengetahuan, sekaligus menjadi tempat rekreasi yang bermanfaat bagi semua kalangan. Banyaknya buku yang tersedia menuntut sistem pelayanan perpustakaan yang baik dan tertata rapi. Pelayanan yang diberikan harus dapat mempermudah para user dalam melakukan peminjaman serta pencarian lokasi buku yang tentunya berada di dalam rak buku yang sangat luas. Minimnya pelayanan perpustakaan yang berjalan saat ini, 
tentunya membuat para user kesulitan dalam mencari buku yang mereka inginkan. Oleh karena itu perlu dibuatkan suatu alat yang dapat menunjukan arah buku dan mempermudah user dalam melakukan pencarian lokasi buku. Perkembangan teknologi dapat dimanfaatkan sebagai salah satu cara untuk mempermudah user dalam melakukan pencarian lokasi buku. Teknologi elektronika dapat membantu dalam pembuatan suatu alat penunjuk arah lokasi buku. Dengan alat ini, user hanya perlu menyebutkan judul buku yang mereka inginkan kepada penjaga perpustakaan. Setelah itu penjaga perpustakaan akan memberikan nomor rak tempat buku disimpan. Nomor rak tersebut yang nantinya akan menjadi perintah pada robot untuk berjalan mengikuti lintasan atau garis menuju lokasi, dimana prinsip kerja alat ini sering disebut dengan Sistem Line Follower. Line Follower itu sendiri berarti robot atau alat yang bisa berjalan mengikuti garis . Setelah itu User harus menekan keypad pada robot sesuai dengan nomor rak, dan robot akan berjalan menunjukan lokasi buku yang di inginkan. Teknologi yang canggih pada masa kini sangat dicari. Inovasi demi inovasi diciptakan oleh anak-anak bangsa untuk kemajuan negeri tercinta. Kemajuan teknologi yang canggih juga diharapkan implementasiannya dalam Perpustakaan. Dalam hal ini peneliti berusaha mengaplikasikan kemajuan teknologi yang efisien dalam sistem kerja di Perpustakaan Kota Tangerang dengan memperhatikan lingkungan kerja. Konsep Robotik yang belakangan ini sering digunakan dalam berbagai unsur dalam kehidupan manusia.

Banyak penelitian yang sebelumnya dilakukan mengenai Line Follower. Penelitian yang dilakukan oleh Muhammad Arif Prayudi, Edy Victor Haryanto Sianturi, Iwan Fitrianto Rahmad, dan Khairul Ummi dari STMIK Potensi Utama Medan. Perancangan Robot Line Follower Pemisah Benda Berdasarkan Warna Berbasis Mikrokontroler ATMega16. Penelitian ini membahas tentang robot Line Follower yang mampu mendeteksi warna dari sebuah objek, dan meletakkan objek tersebut pada tempatnya sesuai warna yang di deteksi. Penelitian yang dilakukan oleh Achmad Zakki Falani, dan Setyawan Budi dari Universitas Narotama Surabaya yang berjudul Robot Line Follower Berbasis Mikrokontroler Atmega 16 dengan Menampilkan Status Gerak Pada LCD. Penelitian ini membahas tentang robot Line Follower yang mampu berjalan mengikuti garis, dan menampilkan status gerakan robot pada sebuah layer LCD. Menurut Ardiyan Rofiq Mulyana, dkk dari Universitas Gadjah membuat ROPADAS (ROBOT PRAMUSAJI CERDAS) BERBASIS LINE FOLLOWER SYSTEM. Penelitian ini membahas tentang robot pramusaji yang memanfaatkan teknologi Line Follower yang mampu berjalan mengikuti garis mengantarkan makanan atau melayani para pembeli. Penelitian yang dilakukan Daisy A.N Janis dari Universitas Sam Ratulangi Manado yang berjudul Rancang Bangun Robot Pengantar Makanan Line follower. Penelitian ini membahas tentang pemanfaatan Line Follower yang di fungsikan sebagai robot pengantar makanan. Menurut Abdulmuttalib T. Rashidyang Electrical Engineering Dept. University of Basrah Basrah, Iraq mengatakan dengan Design and Construction Objects Store System using Line Follower Robot, membahas tentang metode baru untuk menyimpan objek dalam statis lingkungan, disebut sebagai sistem penyimpanan objek, dirancang dan dibangun. Sistem ini terdiri dari tiga puluh kotak yang disusun dalam empat kolom untuk menyimpan dan mengambil objek menggunakan garis robot pengikut. Proses penyimpanan dan pengambilan adalah diselidiki dengan menggunakan drive mobile robot diferensial yang dilengkapi dengan sensor inframerah kiri dan kanan untuk bekerja sebagai garis robot pengikut. Lintasan robot ini diatur sesuai dengan algoritma pohon $\mathrm{N}$-ary dan ditingkatkan dengan menggunakan Algoritma diferensial digital DDA untuk mengurangi rabbies kejadian. Alamat setiap kotak toko dianggap sebagai kode akses dengan lima digit biner yang melindungi dengan menggunakan modul identifikasi frekuensi radio (RFID). Benda-benda itu sistem toko diimplementasikan pada dua skenario eksperimental, salah satunya digunakan untuk menguji waktu kedatangan sehubungan dengan jumlah kotak toko dan yang lainnya digunakan untuk menguji panjang rata-rata jalur.

\section{LITERATUR REVIEW}

1. Penelitian yang dilakukan oleh Rakesh Chandra Kumar, Md. Saddam Khan, Dinesh Kumar,Rajesh Birua,Sarmistha Mondal, Manas Kr.Parai dari Siliguri Institute Of Technology India yang berjudul " OBSTACLE AVOIDING ROBOT “ pada tahun 2013. Penelitian ini membahas tentang robot pengikut garis atau line follower yang mampu menghindari rintangan yang ada di depannya dengan menggunakan sensor ultrasonik. 
2. Penelitian yang dilakukan oleh Santoso Santoso, Saadilah Mursyid yang dari Politeknik Negeri Tanah Laut yang berjudul " KONTROL PROPORTIONAL INTEGRAL (PI) PADA ROBOT LINE FOLLOWER" pada tahun 2015. Penelitian ini membahas tentang pengimplematasian sistem kontrol PI (proportional Integral), pada sistem gerak robot line follower menggunakan motor DC berbasis mikrokontroller Atmega 328a, menggunakan 8 sensor garis dengan memanfaatkan LED dan Photodioda, kontrol PI mampu menghasilkan gerak robot mengikuti garis dengan gerak lebih presisi dibanding dengan hanya mempergunkan kontrol P saja, dengan menentukan konstanta $\mathrm{Kp}$ dan Ki kecepatan motor terjaga pada nilai yang diinginkan, gerakan robot mengikuti garis sesuai dengan kecepatan dan kestabilan posisi.

3. Penelitian yang dilakukan oleh Muhammad Yusuf, Isnawaty, dan Rahmat Ramadhan dari Universitas Halu Oleo Kendari yang berjudul "Implementasi Robot Line Follower Penyiram Tanaman Otomatis Menggunakan Metode Proportional-Integral-Derivative Controller (PID)" pada tahun 2016. Penelitian ini membahas tentang robot penyiram tanaman berbasis line follower menggunakan kontrol gerak PID (Proportional-Integral- Derivative Controller).

4. Penelitian yang dilakukan oleh Wira Hidayat Mohd Saad, Saiful Anuar Abd. Karim, Norliana Azhar, Zahariah Manap, Yew Yuan Soon, Masrullizam Mat Ibrahim yang berjudul "Line Follower Mobile Robot for Surveillance Camera Monitoring System" pada tahun 2018. Penelitian ini membahas tentang sistem pemantauan kamera pengawasan ponsel. Sistem robotik ini diperkenalkan untuk membantu dalam memecahkan masalah cakupan terbatas yang dihadapi oleh kamera pengintai konvensional yang biasanya dipasang pada posisi tetap. Pengikut lini dipilih untuk menyediakan gerakan mobile dari sistem pemantauan pengawasan. Selain tujuan pengawasan, kamera juga berfungsi untuk mendeteksi segala jenis hambatan pada rute. Rute dan tugas khusus dirancang untuk sistem robot untuk menguji fungsionalitasnya. Ini menunjukkan bahwa sistem robot berhasil menyelesaikan jalur yang dirancang dan berhasil mendeteksi hambatan.

5. Penelitian yang dilakukan oleh Deepak Punetha, Neeraj Kumar, Vartika Mehta yang berjudul "Development and Applications of Line Following Robot Based Health Care Management System " pada tahun 2013. Penelitian ini membahas tentang robot yang dapat menuju setiap ruangan pasien di rumah sakit. Robot ini berbasis line follower yang difungsikan sebagai pelayan atau suter pada rumah sakit.

\section{PEMECAHAN MASALAH}

Untuk mengatasi masalah diatas, maka perlu dibuatkan suatu alat yang mampu menunjukan lokasi buku pada perpustakaan. Sehingga, akan mempermudah para pengunjung dalam proses pencarian buku yang mereka inginkan.

1. Pengunjung menekan push button yang tersedia pada alat, untuk memerintahkan alat supaya bisa berjalan.

2. Pengunjung mengikuti alat yang akan menunjukan lokasi bidang buku.

3. Setelah sampai di lokasi, alat akan mengeluarkan output informasi berupa suara yang akan menjelaskan lokasi buku.

4. Setelah itu, alat akan otomatis berjalan ke lokasi semula untuk melayani pengunjung lainnya.

Setelah melakukan penelitian tentang prosedur yang berjalan saat ini pada Perpustakaan Kota

Tangerang, selanjutnya akan dibahas mengenai rancangan prosedur sistem yang di usulkan. Ada beberapa prosedur yang akan dijabarkan untuk memudahkan proses pencarian buku pada perpustakaan. Prosedur tersebut yaitu sebagai berikut :

1. Pengunjung menekan push button yang tersedia pada alat, untuk memerintahkan alat supaya bisa berjalan.

2. Pengunjung mengikuti alat yang akan menunjukan lokasi buku.

3. Setelah sampai di lokasi, alat akan mengeluarkan output informasi berupa suara yang akan menjelaskan lokasi buku.

4. Setelah itu, alat akan otomatis berjalan ke lokasi semula untuk melayani pengunjung lainnya. 
Diagram Blok

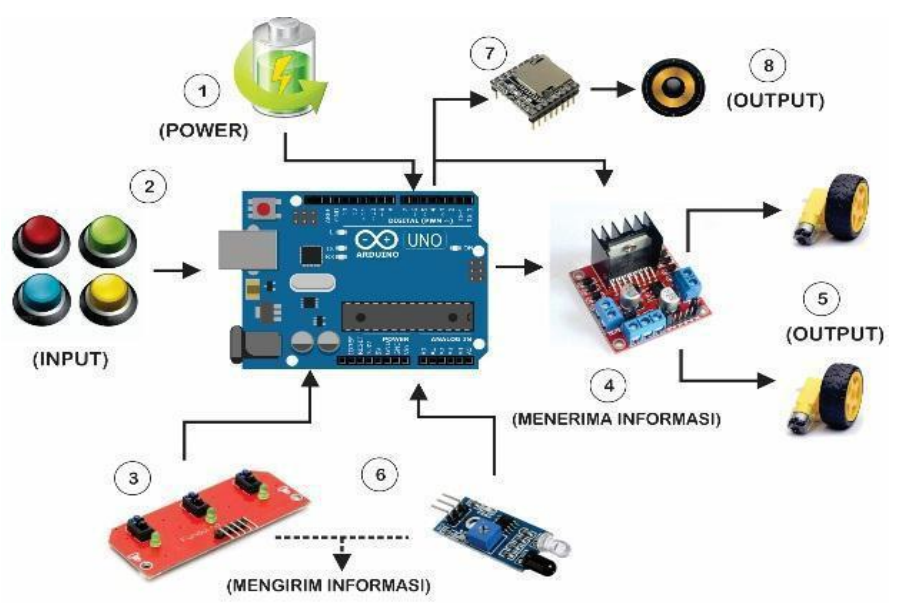

Gambar 1. Diagram Blok Rangkaian

Pada diagram blok diatas digambarkan alur kerja dari sistem mulai dari input, proses, dan output. Keterangan diagram blok rangkaian:

1. Pada alat pertama terdapat sebuah batre yang berfungsi sebagai penyalur daya untuk arduino uno dan motor driver.

2. Sistem dimulai dari sebuah input berupa tekanan pada push button yang dilakukan oleh pengunjung.

3. Setelah itu, input akan diproses dan kemudian akan memerintahkan sensor garis untuk membaca garis sesuai lokasi yang ditekan pada push button. Sensor garis akan mengirimkan informasi pembacaan lintasan kepada arduino uno.

4. Informasi tersebut akan di olah oleh arduino yang kemudian diteruskan menjadi sebuah perintah kepada motor driver untuk menggerakan kedua motor dc sebagai output.

5. Output berupa pergerakan motor dc untuk berjalan menuju lokasi buku.

6. Ketika alat sedang berjalan, sensor ultrasonik akan mengirimkan informasi berupa deteksi objek yang ada di depannya. Alat akan otomatis berhenti sejenak saat ada halangan atau objek yang menghalangi pergerakan alat, dan akan berjalan kembali ketika halangan telah hilang.

7. Alat ini berupa modul mp3 dan berfungsi untuk menyimpan file mp3 yang nantinya akan diputar ketika alat telah sampai pada lokasi buku.

8. Ketika alat sampai paada lokasi tujuan, maka speaker akan mengeluarkan suara dari file mp3 yang terdapat pada modul $\mathrm{mp} 3$ player.

\section{Cara Kerja Alat}

Cara kerja dari alat penunjuk arah lokasi buku ini dapat dibagi menjadi 3 (tiga) bagian. Pada bagian pertama berupa input berupa perintah atau informasi yang kemudian akan di olah atau di proses oleh arduino uno pada bagian kedua. Setelah itu pada bagian ketiga berupa output atau hasil dari perintah yang sudah di olah oleh arduino uno.

1. Sistem Input

Pada sistem input ini berupa tekanan pada push button yang dilakukan oleh pengunjung. Selain itu terdapat dua alat yang berfungsi sebagai input pengirim informasi mengenai pembacaan lintasan berupa garis dan pendeteksi objek atau halangan. Kedua alat itu berupa sensor garis dan sensor ultrasonik.

2. Sistem Proses

Pada sistem proses menggunakan mikrokontroler berupa arduino uno sebagai pusat pengendali serta pengolah semua informasi untuk diteruskan menjadi sebuah output dari alat. Semua informasi yang berasal dari sistem input, akan di proses oleh arduino dan kemudian dijadikan sebuah perintah kepada alat untuk berjalan mengantarkan pengunjung ke lokasi buku. 
3. Sistem Output

Hasil dari semua proses tersebut akan menjadi sebuah output berupa pergerakan motor dc untuk berjalan menuju lokasi. Selain itu terdapat output kedua berupa suara yang akan memberi informasi ketika alat telah sampai di lokasi tujuan, suara tersebut merupakan file mp3 yang terdapat pada modul mp3 player.

\section{a. Flowchart Sistem}

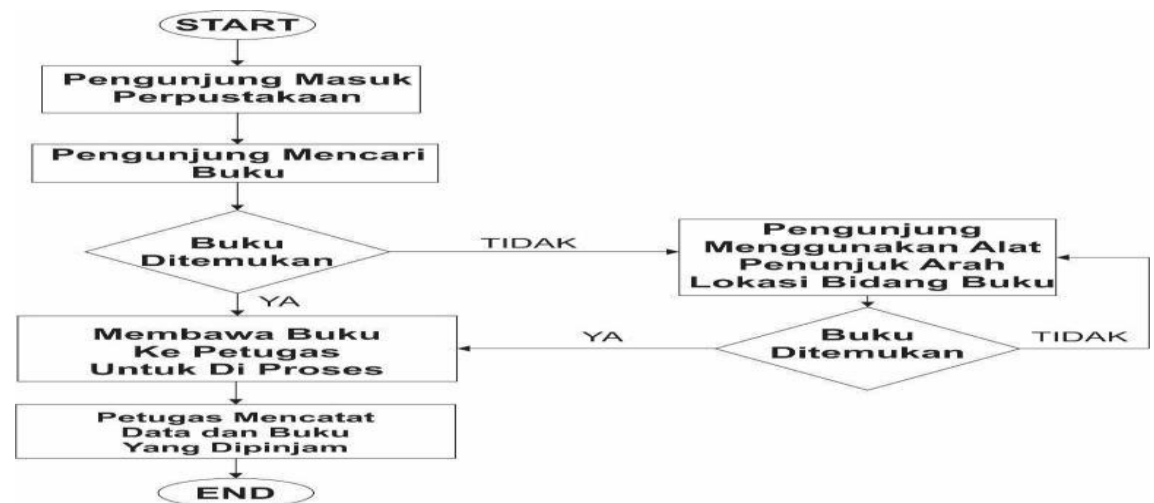

Gambar 2. Flowchart Sistem

Pejelasan flowchart sistem:

1. Pengunjung memasuki ruang perpustakaan

2. Setelah itu pengunjung mencari buku yang mereka inginkan

3. Jika buku sudah ditemukan, maka pengunjung harus menuju petugas untuk melakukan pendataan berupa pencatatan data pengunjung serta buku yang dipinjam,

4. Jika pengunjung kesulitan untuk menemukan buku yang mereka cari, maka pengunjung menggunakan robot yang akan mengantarkan mereka ke lokasi bidang buku yang mereka inginkan.

5. Pengunjung mengikuti robot hingga tiba di lokasi tujuan. Robot akan otomatis kembali ketempat semula ketika telah selesai menunjukan lokasi.

6. Setelah buku ditemukan, pengunjung menuju petugas untuk proses peminjaman.

\section{b. Flowchart Cara Kerja Alat}

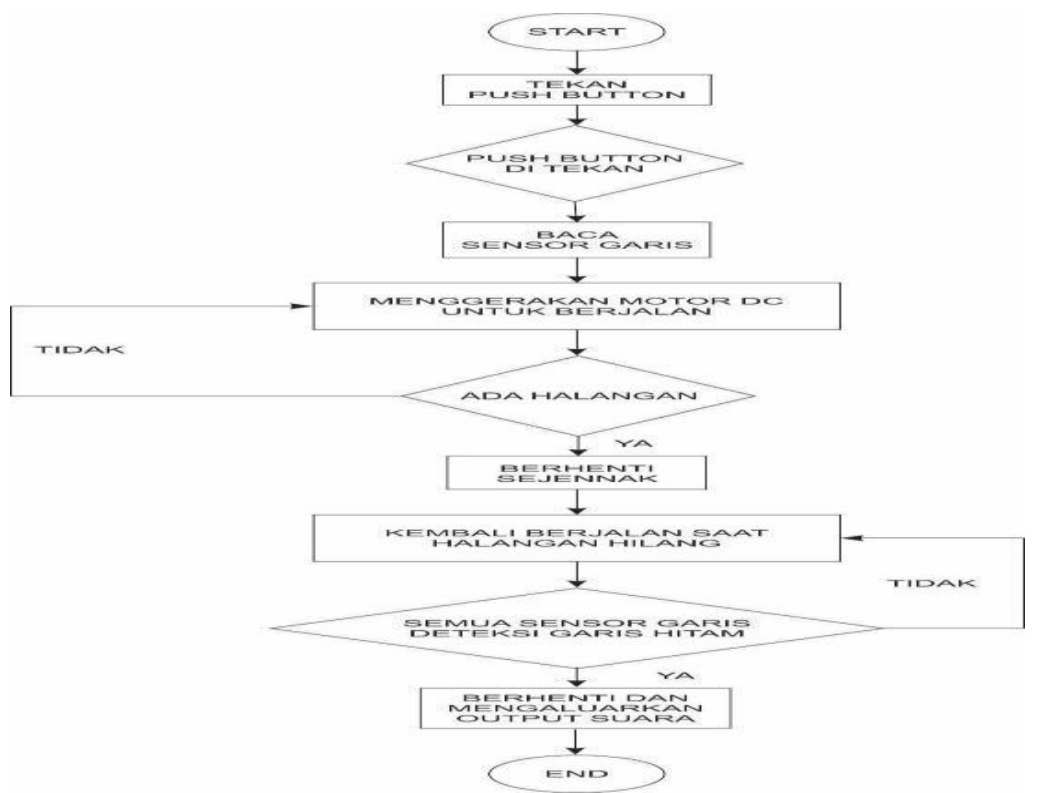

Gambar 3. Flowchart Cara Kerja Alat 
Pejelasan flowchart cara kerja alat:

1. Input berupa push button yang ditekan oleh pengunjung

2. Setelah push button ditekan maka akan memerintahkan sensor garis untuk membaca lintasan

3. Sensor garis membaca lintasan berupa garis hitam.

4. Informasi hasil pembacaan lintasan akan dikirim pada arduino untuk di olah menjadi sebuah perintah yang akan dikirim untuk motor dc.

5. Motor dc akan bergerak menurut perintah yang diberikan arduino berdasarkan hasil pembacaan lintasan.

6. Ketika alat sedang berjalan sensor ultrasonik akan aktif untuk mendeteksi objek atau halangan yang ada di depannya. Robot akan berhenti secara otomatis ketika ada halangan di depannya dan akan kembali berjalan saat halangan telah hilang.

7. Setelah sampai pada lokasi tujuan, maka robot akan berhenti sejenak dan akan mengeluarkan output suara berupa informasi keeradaan lokasi bidang buku yang dituju.

8. Robot akan kembali ketempat semula secara otomatis setelah selesai mengantarkan pengunjung.

\section{IMPLEMENTASI}

Untuk memasukan program ke dalam Arduino uno, diperlukan Driver USB agar Arduino terdeteksi pada komputer, selain itu diperlukan juga sebuah software Arduino.ide 1.8.2 untuk menuliskan program dan mengupload program tersebut ke dalam Arduino uno. Setelah semuanya tersedia maka langkah selanjutnya adalah menghubungkan Arduino uno dengan komputer menggunakan kabel USB, dan mengupload program yang sudah kita tulis sebelumnya. Proses listing program dan upload terlihat pada gambar dibawah ini:

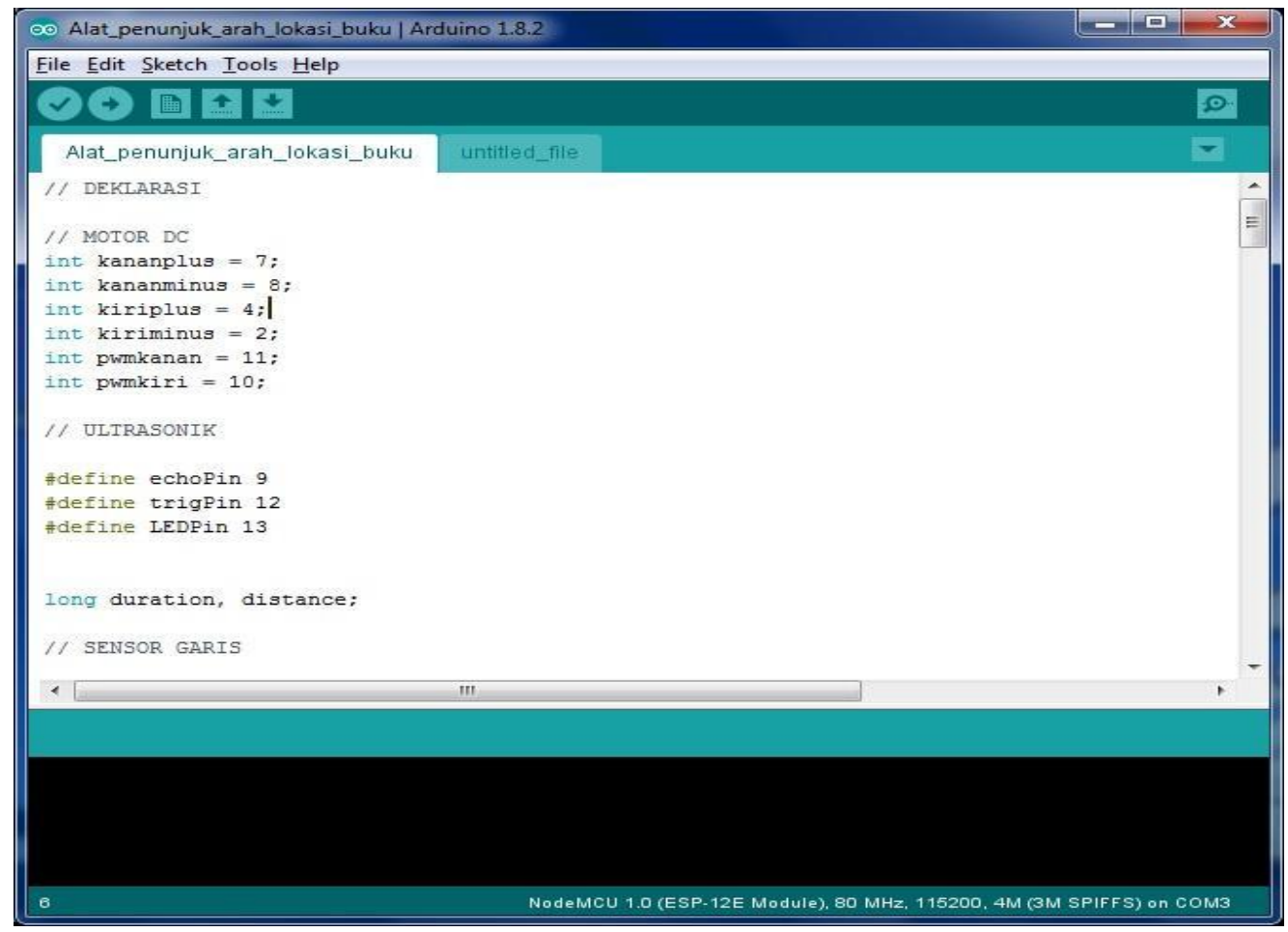

Gambar 4. Listing Program Arduino

\section{TABEL HASIL PENGUJIAN ALAT}

Tabel 1. Pengujian Black Box Pada Sensor

\begin{tabular}{|l|l|l|lr|l|}
\hline No & Nama Form & Kondisi Pengujian & Hasil Pengujian & Keterangan \\
\hline 1 & Sensor & Diberi objek di depan & Mendeteksi objek dan & VALID \\
\hline
\end{tabular}




\begin{tabular}{|c|c|c|c|c|}
\hline & Ultrasonik & sensor & $\begin{array}{l}\text { menampilkan jarak objek pada } \\
\text { serial monitor arduino }\end{array}$ & \\
\hline 2 & Sensor Garis & \begin{tabular}{lr} 
Diuji & \multicolumn{2}{c}{ menggunakan } \\
Solatip hitam pada \\
permukaan & lantai \\
berwarna putih &
\end{tabular} & $\begin{array}{l}\text { Mendeteksi garis hitam berupa } \\
\text { solatip. }\end{array}$ & VALID \\
\hline 3 & Motor DC & $\begin{array}{l}\text { Diberi perintah melalui } \\
\text { motor driver }\end{array}$ & $\begin{array}{l}\text { Bergerak maju atau mundur sesuai } \\
\text { perintah yang diberikan }\end{array}$ & VALID \\
\hline 4 & Keypad & $\begin{array}{l}\text { Ditekan pada setiap } \\
\text { tombol }\end{array}$ & $\begin{array}{l}\text { Menampilkan output tombol yang } \\
\text { ditekan pada serial monitor } \\
\text { Arduino. }\end{array}$ & VALID \\
\hline
\end{tabular}

\section{KESIMPULAN}

Peneliti membuat sebuah robot penunjuk arah lokasi bidang buku berupa robot line follower yang dilengkapi dengan sensor ultrasonik untuk mendeteksi halangan agar tidak menabrak dan sebuah modul mp3 untuk mengeluarkan output berupa suara yang berisi keterangan lokasi buku. Robot ini akan mengantarkan pengunjung menuju lokasi bidang buku yang mereka inginkan, dengan adanya robot ini akan mempermudah pengunjung serta petugas perpustakaan tanpa harus mengarahkan dan mengantarkan pengunjung yang kesulitan. Dalam meningkatkan mutu pelayanan kepada pengujung perpustakaan, diperlukan fasilitas yang dapat mempermudah setiap pengunjung perpustakaan khususnya dalam proses pencarian lokasi buku. Telah diketahui penerapan proses pencarian lokasi buku masih berjalan secara manual. Pengunjung harus mencari sendiri, bertanya kepada petugas, atau meminta untuk diantarkan menuju lokasi buku yang mereka inginkan. Tentunya hal ini berjalan kurang efektif serta memakan waktu yang cukup lama. Selain itu, proses manual seperti ini akan menambah beban kerja terhadap petugas perpustakaan yang harus mengarahkan atau mengantarkan setiap pengunjung yang kesulitan mencari lokasi buku. Peneliti membuat sebuah robot penunjuk arah lokasi bidang buku berupa robot line follower yang dilengkapi dengan sensor ultrasonik untuk mendeteksi halangan agar tidak menabrak dan sebuah modul mp3 untuk mengeluarkan output berupa suara yang berisi keterangan lokasi buku. Robot ini akan mengantarkan pengunjung menuju lokasi bidang buku yang mereka inginkan, dengan adanya robot ini akan mempermudah pengunjung serta petugas perpustakaan tanpa harus mengarahkan dan mengantarkan pengunjung yang kesulitan. Dengan adanya robot ini dapat membantu meningkatkan mutu pelayanan yang diberikan kepada pengunjung dengan menyediakan fasilitas yang dapat mempermudah pengunjung dalam pencarian lokasi buku.

\section{SARAN}

Saran peneliti diharapkan sistem ini bisa dikembangkan lebih lanjut agar bisa memudahkan manusia mengerjakan sesuatu dengan praktis dan efisien. Dan sistem kontrol ini diharapkan mampu mempermudah apapun.

\section{DAFTAR PUSTAKA}

[1] Prayudi, Muhammad Arif., 2014. Perancangan Robot Line Follower Pemisah Benda Berdasarkan Warna Berbasis Mikrokontroler ATMega16. Creative Information Technology Journal, Vol. 1, No. 3. ISSN: 2354-5771. STMIK Potensi Utama Medan

[2] Falani, Achmad Zakki., Setyawan Budi. 2015. "Robot Line Follower Berbasis Mikrokontroler Atmega 16 dengan Menampilkan Status Gerak Pada LCD." e-Jurnal NARODROID, Vol. 1 No.1. E-ISSN : 2407-7712. Universitas Narotama Surabaya

[3] Mulyana, Ardiyan Rofiq. Luthfi Yahya , Rilla Khoirunnisa , Claricha Audi Tamara 2013.“ ROPADAS (ROBOT PRAMUSAJI CERDAS) BERBASIS LINE FOLLOWER SYSTEM ”. Universitas Gadjah Mada. Yogyakarta. 
[4] Janis, Daisy AN., David Pang, Janny O Wuwung. 2014. "Rancang Bangun Robot Pengantar Makanan Line follower".e-journal Teknik Elektro dan Komputer 3, no. 1 ISSN: 2301-8402. Universitas Sam Ratulangi, Manado.

[5] Kumar, Rakesh Chandra, Md. Saddam Khan, Dinesh, Kumar, Rajesh Birua, Sarmistha, Mondal, Manas Kr.Parai. 2013. "OBSTACLE AVOIDING ROBOT. International Journal of Advanced Research in Electrical, Electronics and Instrumentation Engineering Vol. 2, Issue 4 ISSN (Print) : 2320 - 3765 ISSN (Online): 2278- 8875. Siliguri Institute Of Technology India.

[6] Santoso, S., \& Mursyid, S. (2017). KONTROL PROPORTIONAL INTEGRAL (PI) PADA ROBOT LINE FOLLOWER. Jurnal Sains dan Informatika, 1(1), 10-10.

[7] Yusuf, Muhammad., Isnawaty, Rahmat Ramadhan. 2016. Implementasi Robot Line Follower Penyiram Tanaman Otomatis Menggunakan Metode Proportional-Integral-Derivative Controller (PID). Jurnal semanTIK, Vol.2, No.1 ISSN : 2502-8928 (Online). Universitas Halu Oleo Kendari.

[8] Saad, W. H. M., Karim, S. A. A., Azhar, N., Manap, Z., Soon, Y. Y., \& Ibrahim, M. M. (2018). Line Follower Mobile Robot for Surveillance Camera Monitoring System. Journal of Telecommunication, Electronic and Computer Engineering (JTEC), 10(2-7), 1-5.

[9] Punetha, Deepak., Neeraj Kumar, Vartika Mehta. 2013. Development and Applications of Line Following Robot Based Health Care Management System. International Journal of Advanced Research in Computer Engineering \& Technology (IJARCET) Volume 2, Issue 8 ISSN : $2278-1323$.

[10] Rashid, A. T., Ali, F. R., \& Rashid, O. T. (2018). Design and Construction Objects Store System using Line Follower Robot. system, 181(15). 